\title{
RHEOLOGICAL BEHAVIOUR OF CLAYS IN PLASTIC STATE
}

\author{
Jhon Fredy Rincón-Morantes ${ }^{1 *}$ - Javier Camacho Tauta ${ }^{2}$ - Oscar Javier Reyes-Ortiz ${ }^{2}$ \\ ${ }^{1}$ Department of Applied Sciences, Faculty of Engineering, Universidad Militar Nueva Granada, Bogotá D.C., 11011, \\ Colombia. \\ ${ }^{2}$ Department of Civil Engineering, Faculty of Engineering, Universidad Militar Nueva Granada, Bogotá D.C., 11011, \\ Colombia.
}

\begin{tabular}{|c|c|}
\hline ARTICLE INFO & Abstract: \\
\hline $\begin{array}{l}\text { Article history: } \\
\text { Received: } 14.8 .2019 . \\
\text { Received in revised form: } 12.11 .2019 . \\
\text { Accepted: } 18.11 .2019 .\end{array}$ & \multirow{3}{*}{$\begin{array}{l}\text { Clayey soils exhibit viscoelastic behaviour in the plastic state, } \\
\text { implying simultaneous retentive and dissipative mechanical } \\
\text { properties as well as strain rate dependent properties. Such } \\
\text { response is partially captured by the so-called Atterberg plastic } \\
\text { limits. A more comprehensive evaluation of the mechanical } \\
\text { response of this type of soils in the plastic state can be obtained by } \\
\text { testing in a dynamic shear rheometer. Clayey soils consisting of } \\
\text { different proportions of kaolin and bentonite and different water } \\
\text { contents were subjected to dynamic shear tests to measure their } \\
\text { rheological properties. All tests were performed with a constant } \\
\text { strain amplitude of } 10 \% \text {, a fixed range frequency sweep ( } 0.1 \mathrm{~Hz} \text { to } \\
\text { 100 Hz) and a constant temperature of } 20^{\circ} \mathrm{C} \text {. The results show that } \\
\text { the complex shear modulus has an inverse relationship with the soil } \\
\text { water content and a direct relationship with the plasticity index. } \\
\text { Moreover, the phase angle increases slightly and then decreases } \\
\text { suddenly as the frequency increases. The complex shear moduli } \\
\text { obtained by dynamic tests were compared with the oedometric } \\
\text { moduli estimated by correlations and showed satisfactory trends } \\
\text { between them. The study contributed to the understanding of the } \\
\text { complex behaviour of soils in the plastic state. Although the } \\
\text { mechanical response of these materials is affected by some factors, } \\
\text { the plasticity limits were consistent with the complex moduli under } \\
\text { analogous conditions of strain and frequency. }\end{array}$} \\
\hline $\begin{array}{l}\text { Keywords: } \\
\text { Rheology } \\
\text { Clay } \\
\text { Complex modulus } \\
\text { Phase angle } \\
\text { Plastic state }\end{array}$ & \\
\hline DOI: https://doi.org/10.30765/er.1503 & \\
\hline
\end{tabular}

\section{Introduction}

Clayey soils are found in the construction industry and in infrastructure works both as foundation supports and as building materials. Atterberg [1] stated that the plasticity of clay soils is a property that depends on the water content of the soil and is used to explain the consistency of the soil mass. Soil plasticity is the ability to resist cracking and deformation of a soil sample. Plasticity limits are useful properties to better understand the behaviour of fine-grained soils.

The most important application of Atterberg limits is soil classification according to the so-called Unified Soil Classification System (USCS). It is used to distinguish soils based on their particle size distribution and their interaction with water. Several researchers have established correlations between plasticity limits and other properties of soils. For several decades, scientists and engineers have studied correlations between plasticity limits and a variety of physical and mechanical properties. For example, Wroth and Wood [2] have shown that undrained shear strength correlates with liquidity index and compression index correlates with liquid limit. On the other hand, the liquid limit can be related to the mineralogy of the clay [3] and the grain size distribution.

\footnotetext{
* Corresponding author.

E-mail address: u7700110@unimilitar.edu.co
} 
Taking into account the above, some proposals have been developed to study clayey materials using rheological techniques and various laboratory methods, since the clay soil exhibits a behaviour between an ideal elastic solid and an ideal viscous fluid, depending on the water content with respect to the fluid and plastic limits [4]. These moist clay soils exhibit a physical and rheological behaviour characteristic of a viscoelastic material, since the solid part interacts with different activities depending on its moisture or dispersion phase [5].

Other complex rheological tests use other devices such as the rotational viscometer or the rotational rheometer. These devices have been used to demonstrate that at high strain rate and low water content, the elastic component of the deformation increases, while at higher moisture contents, the shear modulus and viscosity decrease [6].

A type of rotational rheometer is the dynamic shear rheometer (DSR). With the DSR is possible to study the rheological properties of clayey soils under a variety of conditions [4]. It is necessary to perform many tests in samples with different plasticity indexes and water contents to understand the rheological properties of these soils. Such a test campaign could be useful to find relationships between the liquidity index and shear modulus.

The work shown in this paper includes the physical and dynamic characterisation of four types of clays product of mixing different amounts of kaolin and bentonite. The physical characterisation includes specific gravity of solids $\left(G_{S}\right)$, water content $(w)$, plastic limit $(P L)$ and liquid limit $(L L)$. Dynamic characterisation comprises measurement of complex shear modulus $\left(G^{*}\right)$ for different frequencies $(\omega)$ by using the DSR equipment for a detailed rheological analysis of clays under four different water contents.

The objective of this work is to develop an alternative for the analysis of elastic and viscous properties of clayey soils. The Atterberg limits and the indices derived from them were compared with different components of the complex modulus. Finally, the complex moduli were compared with the oedometric moduli estimated by correlations, showing satisfactory trends between them.

\section{Background}

\subsection{Consistency limits}

In geotechnical engineering, some researchers have studied the concepts developed by Atterberg to understand the behaviour of clay soils. The plastic limit $(P L)$ is the water content where the soil stops behaving solidly. The liquid limit $(L L)$ is the water content that represents the lower limit of the viscous behaviour of clay. The difference between these limits is called the plasticity index $(P I)$. The liquidity index $(L I)$ allows knowing if the sample is in a plastic state $(L I=0 \%)$ or liquid state $(L I=100 \%)$ for different $P I$ (see equation 1$)$.

$$
L I=\frac{w-P L}{L L-P L}
$$

A mechanical method was developed by Casagrande to estimate the liquid limit, [7]. The liquid limit is the water content that the soil needs to close a groove $(2 \mathrm{~mm})$ with 25 blows in the Casagrande cup. The test is carried out at two blows per second equivalent to a frequency of $2 \mathrm{~Hz}$. When dividing the soil sample of 8mmhigh, the soil has to slide $1 \mathrm{~mm}$ horizontally until touching the opposite slope. Hence, the maximum unit shear strain is approximately $12.5 \%$ (see Figure 1 ).

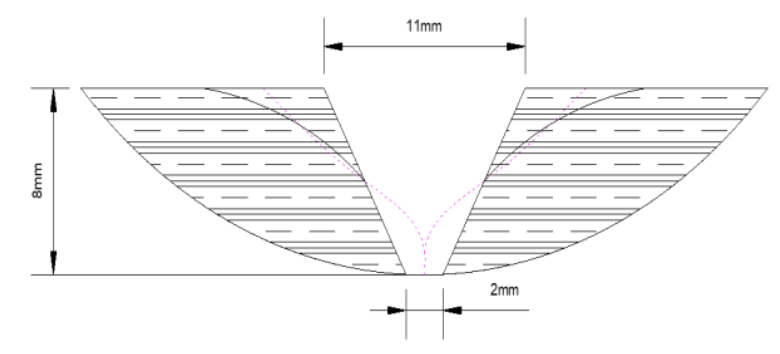

Figure 1. Front view of a soil sample in the Casagrande brass cup. 


\subsection{Rheology}

As already mentioned, clayey soils with water content above the plastic limit can behave like a linear viscoelastic model because they combine the properties of a viscous and an elastic material. Viscosity is the property of dissipating the energy associated with irreversible deformation by the sliding of molecular chains. Elasticity is the property of storing energy as the molecular chains move on a small scale, preventing the particles from flowing [8].

Then, by rheological analysis is possible to analyse the response of clays to a cyclic shear strain. The response can be described as a complex relation (see equation 2) [9], [10], in which $\sigma$ is shear stress, $\gamma$ is a shear strain and $t$ is time.

$$
\sigma(t)=G^{*}(\omega) \cdot \gamma(t)
$$

The complex modulus is the vector summation of the elastic and viscous moduli [11] (see equation 3):

$$
G^{*}=G^{\prime}+i G^{\prime \prime}
$$

where:

$G^{\prime}$ : elastic or storage modulus

$G^{\prime \prime}:$ viscous or loss modulus

$i: \sqrt{ }-1$

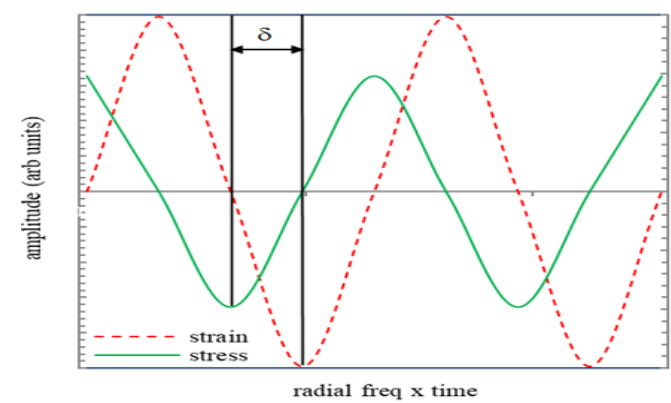

Figure 2. The response of a viscous system to an oscillatory strain or stress. Adapted from Goodwin and Hughes [12].

Another of the measurements that can be made on viscoelastic materials is the phase angle $(\delta)$, which is defined as the lag between applied stress and the response in strain, as can be seen in Figure 2. This angle shows the viscoelastic behaviour and can vary between $0^{\circ}$ and $90^{\circ}$, where the $0^{\circ}$ represents a total elastic response and $90^{\circ}$ a total viscous response (it is the case shown in Figure 2). In certain studies on clay slurries, it has identified that the phase angle for a mineral suspension with bentonite is less than that of kaolin suspension. [13].

In this research, the tests were carried out with a frequency sweep at a constant temperature, given that the frequency dependence of the shear modulus exhibits the same trend as the one that can be seen in Figure 3 .

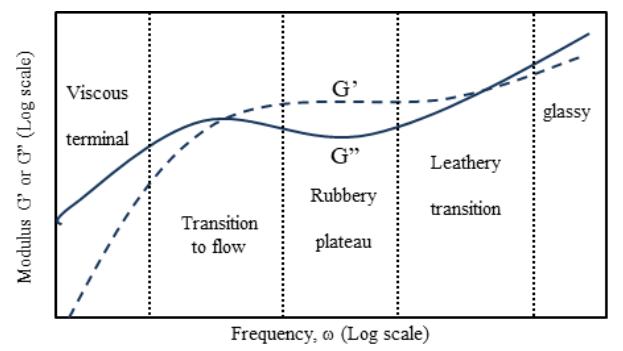

Figure 3. Typical behaviour of a polymer when scanning frequencies. Adapted from Barnes [14]. 


\subsection{Correlations between index and mechanic properties of soils}

Some authors have found different correlations between index properties and geotechnical moduli. Mayne [15] proposed a correlation between the compression index $\left(C_{c}\right)$ and the liquid limit for normally consolidated clays:

$$
C_{c}=0.009(L L-13)
$$

$C_{c}$ is the slope of the normal consolidation line in the e-log $\left(\sigma_{v}^{\prime}\right)$ plane with $e$ : void ratio and $\sigma_{v}^{\prime}$ : vertical effective stress. Favre and Rahma [16] exposed that, Biarez et al. found that a slurry subjected to vertical stress of $6.5 \mathrm{kPa}$ will reach the equilibrium at a water content equal to the liquid limit. This finding and Equation (4) allow to know the location of the normal consolidation line, which let to estimate the effective oedometric modulus $\left(E^{\prime}\right)$ with the following equation:

$$
E^{\prime}=2.3 \frac{1+e}{C_{c}} \sigma_{v}^{\prime}
$$

Effective oedometric modulus could be related to the shear modulus for small strains. For example, Mayne [17] related the effective oedometric modulus with the small-strain shear modulus $\left(G_{0}\right)$ (see equation 6), taking into account a penetration resistance in the in-situ tests. This researcher estimated different coefficients of proportionality $\left(\alpha^{\prime}{ }_{G}\right)$ that can oscillate between 0.02 for organic clays and 2 for overconsolidated quartz sands.

$$
E^{\prime}=\alpha_{G}^{\prime} \cdot G_{0}
$$

\section{Materials and methods}

The kaolin object of this study represents one of the most widespread materials in clayey soils, whose minerals allow them to absorb water or other substances to a large extent and expand [18]. On the other hand, bentonite is made up of highly colloidal clay minerals [19]. This clay has been studied due to its rheological properties to be used as a mineral filler in polymeric compounds, such as bentonite-polyester [20]. Mixtures of kaolin and bentonite composed the soils used in the work. The characterisation of these two materials is summarised in Table 1.

Table 1. Characteristics of the materials.

\begin{tabular}{|c|c|c|c|c|}
\hline Material & $G S$ & $L L$ & $P L$ & $P I$ \\
\hline Kaolin & 2.68 & 41 & 30 & 11 \\
\hline Bentonite & 2.69 & 301 & 75 & 226 \\
\hline
\end{tabular}

These clayey soils were mixed in different proportions to obtain four different soils with several plasticity indexes. The amounts of kaolin and bentonite are presented in Table 2. As demonstrated in other studies [21], when making these type of mixtures, resulting in plasticity limits are not proportional to the relative amounts of each of the components in the mixture. Plasticity limits of the mixtures were obtained according to the ASTM D4318-17e1 standard test [22]. Results are shown in Table 2.

Table 2. Description and characteristics of the mixtures.

\begin{tabular}{|c|c|c|c|c|c|}
\hline Mixture & $\begin{array}{c}\text { Kaolin } \\
(\%)\end{array}$ & $\begin{array}{c}\text { Bentonite } \\
(\%)\end{array}$ & $L L$ & $P L$ & $P I$ \\
\hline 1 & 95 & 5 & 58 & 31 & 27 \\
\hline 2 & 90 & 10 & 76 & 31 & 45 \\
\hline 3 & 70 & 30 & 154 & 36 & 118 \\
\hline 4 & 50 & 50 & 242 & 43 & 199 \\
\hline
\end{tabular}


Four different samples were prepared for each soil mixture, each one with different water content (i.e. different liquidity index) between the plastic limit and the liquid limit. Table 3 shows the liquidity indexes of the sixteen samples obtained for the tested samples of clays. Column A groups liquidity indexes around $0 \%$. Columns B and C, $20 \%$ and 60\%, respectively and Column D samples with liquidity index close to $100 \%$. Liquidity indexes reported in Table 3 were computed from water contents measured after the rheological test and hence there were smalls yet admissible variations between the desired liquidity index and the final one.

Table 3. Liquidity indexes of the samples.

\begin{tabular}{|c|c|c|c|c|}
\hline Mixture & $\begin{array}{c}\text { A } \\
(\%)\end{array}$ & $\begin{array}{c}\text { B } \\
(\%)\end{array}$ & $\begin{array}{c}\text { C } \\
(\%)\end{array}$ & $\begin{array}{c}\text { D } \\
(\%)\end{array}$ \\
\hline 1 & -7 & 16 & 67 & 118 \\
\hline 2 & 5 & 23 & 59 & 97 \\
\hline 3 & 1 & 20 & 58 & 102 \\
\hline 4 & 1 & 22 & 63 & 101 \\
\hline
\end{tabular}

To perform the rheological tests, a DSR was used under the methodology established in AASHTO T 315 10 , to measure the complex shear modulus $\left(\boldsymbol{G}^{*}\right)$ for asphalts [23]. The same process was used by other researchers in previous studies on soils rheology [4]. The only difference in this study regarding the mentioned standard is the gap between plates (i.e. the height of the sample). For asphalts, the gap should be $1 \mathrm{~mm}$, while in this case the gap was adjusted to $2 \mathrm{~mm}$. The complete assembly of the test can be observed in Figure 4 . The controlling parameters used for tests are the following:

- Geometry: $25 \mathrm{~mm}$ in diameter, $2 \mathrm{~mm}$ of the gap between parallel plates. The volume of all the samples is constant during the test.

- The test temperature remains constant at $20^{\circ} \mathrm{C}$ by mean of water circulation within the Peltier plate.

- A controlled sinusoidal sweep of $10 \%$ strain amplitude is applied. The sweep range starts at $0.1 \mathrm{~Hz}$ and stops at $100 \mathrm{~Hz}$.

- An isolation chamber is installed to prevent the flow of air and reduce the evaporation of water from the sample.

- The total time of the test does not exceed 10 minutes. During this period, the maximum loss of moisture was lower than $0.5 \%$.

- The results of the test include storage, loss and complex shear moduli, as well as the phase angle. All these data as a function of frequency.

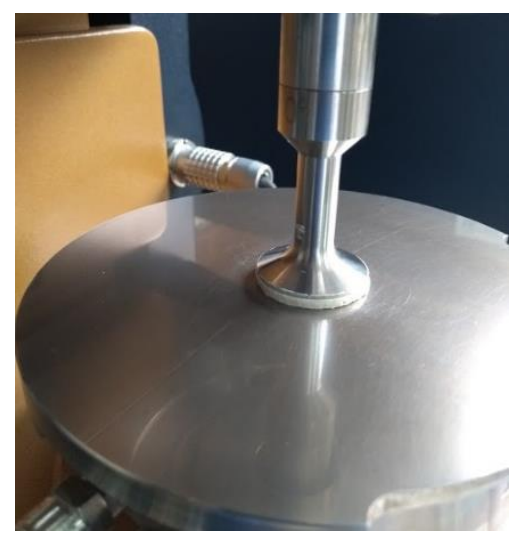

Figure 4. Assembly of the rheological test in clays. 


\section{Results and discussion}

The results of the rheological tests performed by DSR are presented in Figure 5, 6, 7. As can be seen Figure 5 , the complex shear modulus decreases as the liquidity index increases, which confirms that as the samples are more fluid, their shear stiffness is lower.

Likewise, samples with water content close to the plastic limit (i.e. LI $\approx 0 \%$ ) have different behaviour, since in all of these samples there is a zone between $1 \mathrm{~Hz}$ and $10 \mathrm{~Hz}$ where the complex shear modulus has an irregular fall. Particularly, figures 5a) and 5c) diagrams show an anomalous $G^{*}$ behaviour, because samples with less $P I$ and $L I=0$ are more solidly, while the other samples are more liquid (5b) diagram) y with high plasticity (5d) diagram).

In clays with moisture close to the liquid limit (i.e. $L I \approx 100$ ), the complex shear modulus gradually increases with frequency. As the frequency approximates to $100 \mathrm{~Hz}$, the slope has a sudden rise.

The four plots in Figure 5 suggest that for high-plasticity soils $(L L \geq 50)$, the shear modulus is less affected by variations of the liquidity index. In samples with liquidity indexes near $100 \%, G^{*}$ increases from $7 \mathrm{kPa}$ to $20 \mathrm{kPa}$ as the plasticity index increases (For example, in Table 4 shows $G^{*}$ at a frequency of $2 \mathrm{~Hz}$ ). The above in accordance with Cruz [13] that found higher viscosity values in bentonites than in kaolinites. This finding could be related to the colloidal interactions within particles, which is higher in soil mixtures with more bentonite content.

Table 4. $G^{*}$ for samples with $L I \approx 100 \%$ and $2 \mathrm{~Hz}$.

\begin{tabular}{|c|c|c|c|}
\hline Mixture & $P I$ & $\begin{array}{c}L I \\
(\%)\end{array}$ & $\begin{array}{c}G^{*} \\
(\mathrm{kPa})\end{array}$ \\
\hline 1 & 27 & 118 & 8.23 \\
\hline 2 & 45 & 97 & 9.86 \\
\hline 3 & 118 & 102 & 14.68 \\
\hline 4 & 199 & 101 & 17.77 \\
\hline
\end{tabular}

In summary, $G^{*}$ does have the dependence of the frequency, for the samples with liquidity index higher than $20 \%$. This property is characteristic of rubbery materials because the mixed soils have low loss factors by their interactions between solid and liquid phases. Pritz [24] indicated the above affirmation and additionally, he said that is usual to assume that $G^{*}$ is similar to $G^{\prime \prime}$ for viscoelastic materials, as can be analysed in Figure 6.

Figure 6 presents separately the elastic $G^{\prime}$ and viscous $G^{\prime \prime}$ moduli as a function of frequency and liquidity index for the different soils. In accordance with the complex modulus, these moduli decrease as the liquidity index increases.

The samples with water content close to the plastic limit have two behaviours. Tadros [25] explained these behaviours for viscoelastic materials. The first one appears at low frequencies, where $G^{\prime}$ is greater than $G^{\prime \prime}$. This zone is called the rubbery region where the dissipation of energy is reduced. The second behaviour happens at intermediate frequencies, where $G^{\prime \prime}$ is greater than $G^{\prime}$. This range of frequencies is called viscous region in which the samples can dissipate energy. Therefore, it could be said that the clayey soils have diverse kind of interactions between particles for different frequencies. For this research, low frequency is 0.1 to 1.0 $\mathrm{Hz}$, intermediate until $10.0 \mathrm{~Hz}$ and high is $>10 \mathrm{~Hz}$. 


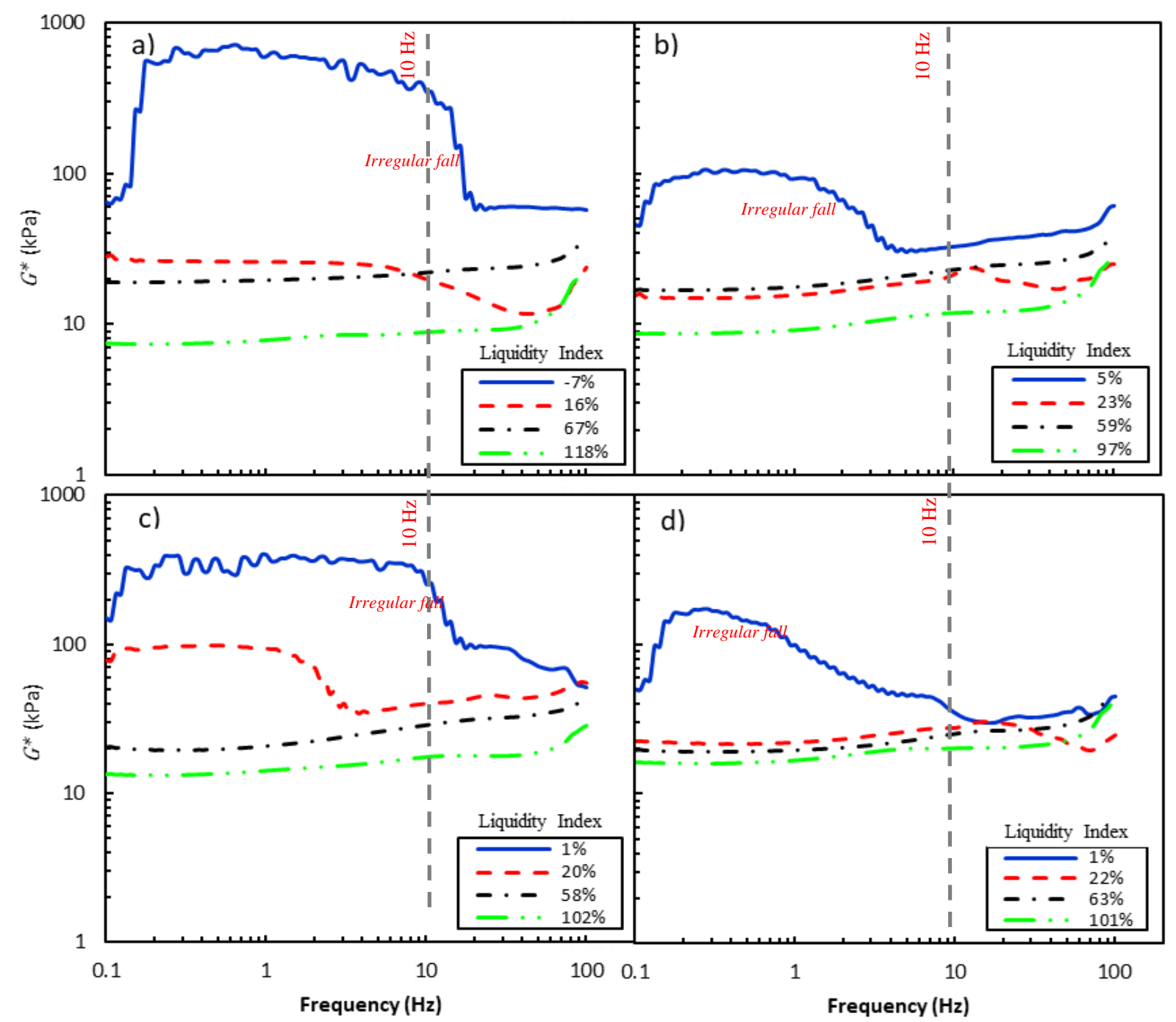

Figure 5. Complex shear modulus for different LI a) Mixture 1, b) Mixture 2, c) Mixture 3 and d) Mixture 4.

$G^{*}, G^{\prime}$ y $G^{\prime \prime}$ depends on the frequency and could be due to the different vibration response between solid particles and the water present in the pores. Biot [26] explained this behaviour, as the kinetic energy dissipation depends only on the relative motion between the fluid and the solid, associated with a frequency and velocity pattern.

At high frequencies, all the mixtures presented a region where $G^{\prime \prime}$ is equal to $G^{\prime}$, in which the intersection is denominated as the transition to flow region. For samples with $L I$ highest to $20 \%$, the viscous modulus $G^{\prime \prime}$ always dominated the elastic modulus $G^{\prime}$ until intermediate frequencies ( 20 to $60 \mathrm{~Hz}$ ). This behaviour is the transition to the flow for the rubbery zone, and it is characteristic of a viscoelastic liquid.

Another research [18] estimated that the cross of elastic modulus $G^{\prime}$ and viscous modulus $G^{\prime \prime}$ is a deformation limit in the strain sweep test. For this analysis, the frequency point in which $G^{\prime}=G^{\prime \prime}$ can be designated as frequency limit. In most of the samples, the frequency limit is higher for soils with low liquidity index, because as the water content approaches to the plastic limit, the mixtures have stronger interparticle connections than in the liquid limit zone.

The mixtures with higher PI resulted in less variation of moduli against frequency. For example, the moduli for samples of mixture 4 are approximately lineal and around $10 \mathrm{kPa}$, while other mixtures are in a range of $10 \mathrm{kPa}$ to $1000 \mathrm{kPa}$. 


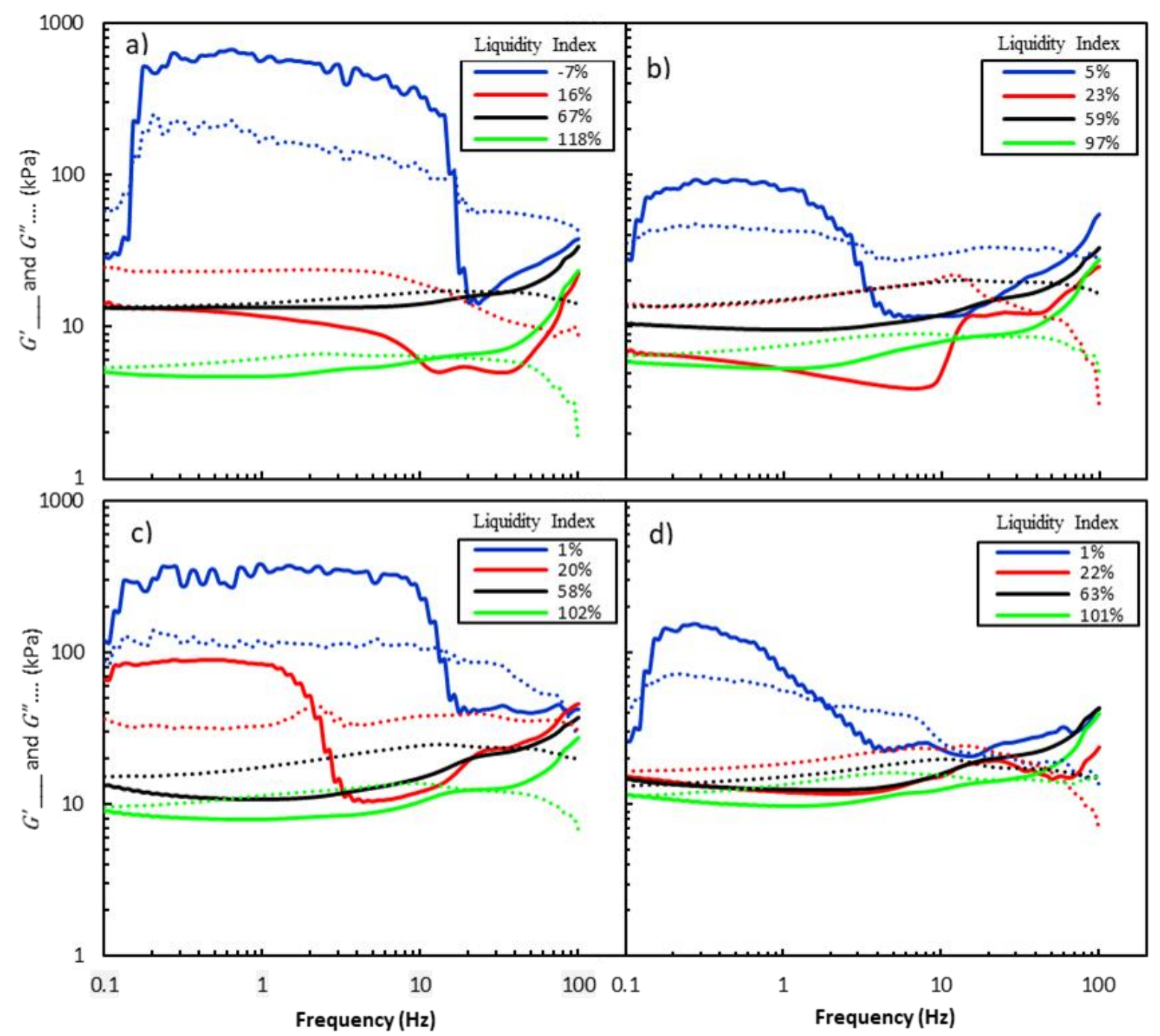

Figure 6. Elastic $\left(G^{\prime}\right)$ and viscous $\left(G^{\prime \prime}\right)$ moduli to different LI a) Mix. 1, b) Mix. 2, c) Mix. 3 and d) Mix. 4.

The phase angles obtained for the mixtures of kaolin with bentonite show an evident dependence of the frequency, as can be seen in Figure 7. Considering that, all the tests at high frequencies (10 to $100 \mathrm{~Hz}$ ), in general, presented a negative slope, representing that, at said frequencies, all materials tend to behave more elastic than viscous. Ghezzehei and Or [4] explained the reason whereby the phase angles decrease at high frequencies. These results are related to frequencies of the test since the applied load was constant, too low frequency provides longer loading time, thus the result is a viscous dissipation or higher phase angle.

The results of the mixtures with $L I$ higher than $20 \%$, low and intermediate frequencies have a positive slope phase angle, and the phase angles are in the medium range $\left(30\right.$ to $\left.60^{\circ}\right)$. This range represents that, the clayey soils are viscoelastic for these frequencies, due to the low frequency of loading, and the relative motion between the fluid and the solid, as explained previously.

Particularly at a frequency of $100 \mathrm{~Hz}$, the mixtures show that with less $P I$, the phase angle is more scattered for different $L I$. Moreover, as bentonite is added ( $P I$ increase), the phase angles for different liquidity indexes approach to $20^{\circ}$. The above observation indicates that the minerals of the bentonite influence in the behaviour of mixes, as Schmitz [3] confirmed in his research. 

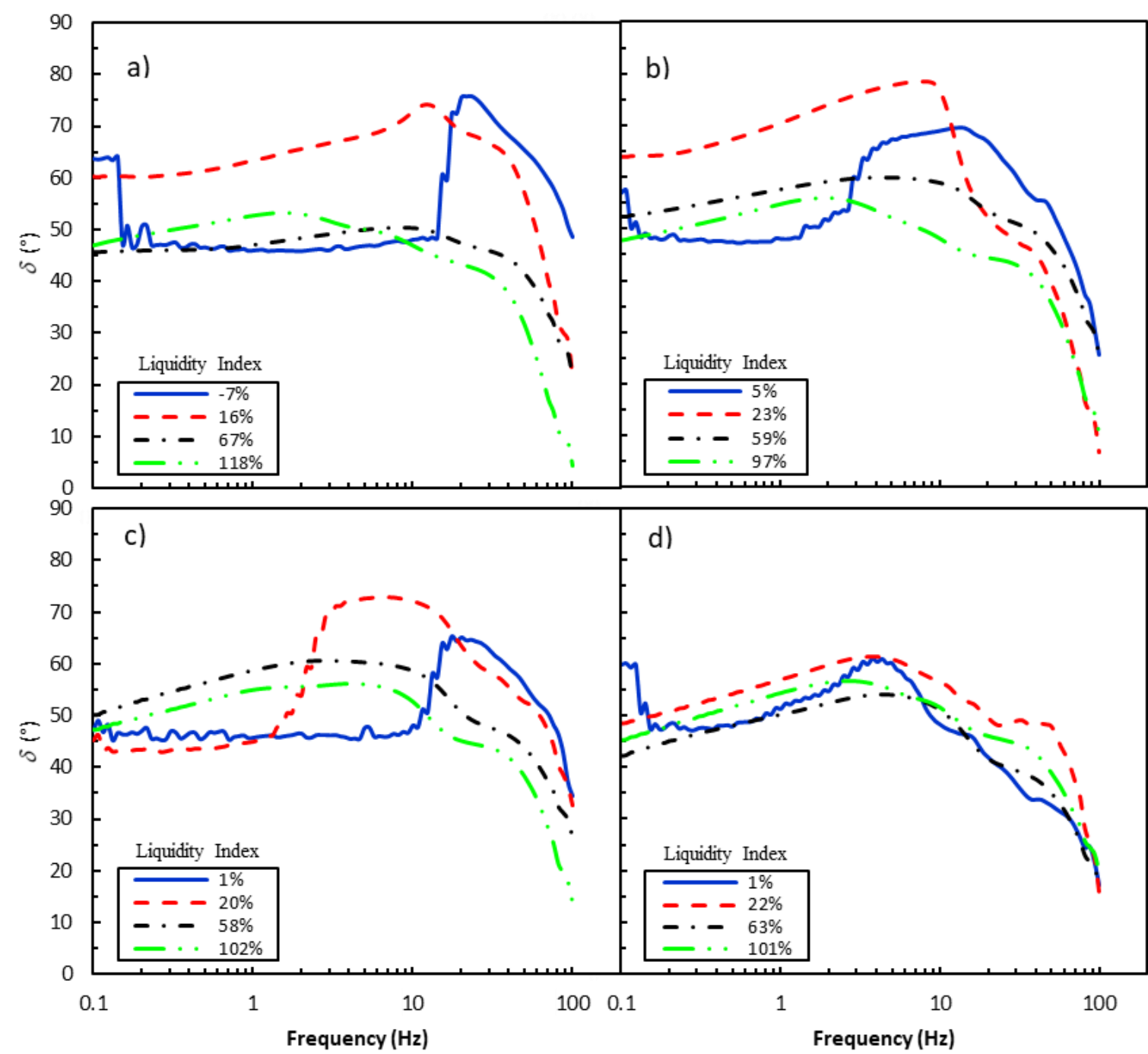

Figure 7. Phase angle ( $\delta$ ) to different LI a) Mixture 1, b) Mixture 2, c) Mixture 3 and d) Mixture 4.

For low and intermediate frequencies, the phase angle of the clayey soils should increase with the $L I$, as a result of the reduced solid-solid interactions, due to the expanded spacing between clay particles. However, results in Figure 7 show that phase angles do not evidence an organized sequence. Precisely, this fact could be caused by the vibration produced between solid and liquid phases and the mineralogy of the clays. Thence that Ghezzehei and Or [4] concluded that the rheological properties of soils are related to the flow of solid-water and microscopic clay structure.

Liquid limit test and the rheology test at $2 \mathrm{~Hz}$ and liquidity index at $100 \%$ were compared. It was expected similar complex moduli for samples with $L I=100 \%$. Nevertheless, Figure 8 and Figure 9 show that samples with less $P I, G^{*}$ tend to decrease. 


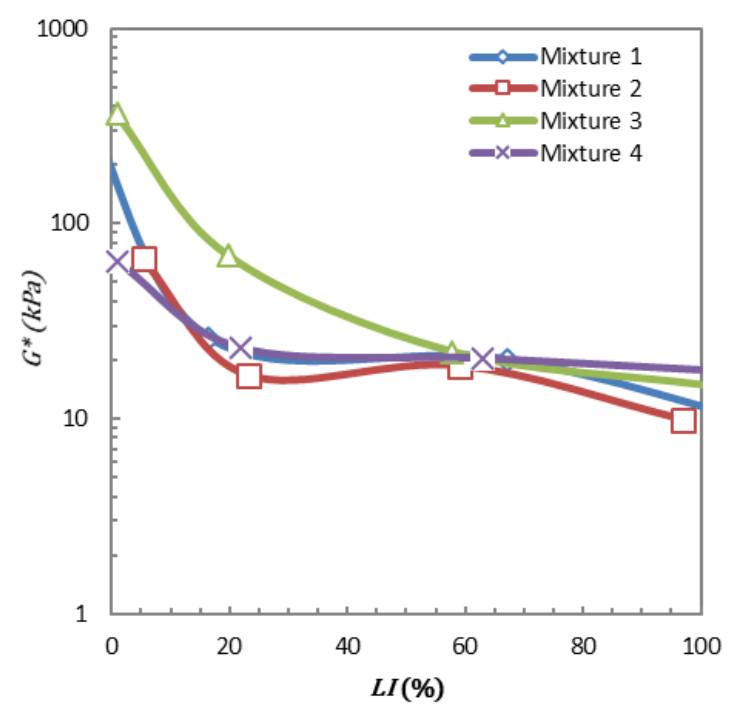

Figure 8. Complex shear modulus $\left(G^{*}\right)$ as a function of LI at a frequency of $2 \mathrm{~Hz}$.

For all the mixtures in Figure 8, the complex modulus decreases abruptly until $L I=20 \%$, acts differently for different mixes when $L I$ is between $20 \%$ and $60 \%$ (for Mixture 2 it slightly increases and for Mixture 3 the decrease is not slight as for the Mixtures 1 and 4). Tadros [25] explained that this trend is due to a dispersion between solid particles caused by the high water content. The mixtures with around $60 \%$ have a similar modulus, but it should be subject for further study.

Figure 9 shows the complex shear modulus of the samples with water content equals in the liquid limit $\left(G_{L L}^{*}\right)$, as explained previously, this condition serves to compare with the conventional Casagrande Test. The complex shear modulus is higher for mixtures with high PI (mixture 4, with $50 \%$ bentonite and $50 \%$ kaolin). Vucetic and Dobry [27] concluded that the plasticity index $(P I)$ is the main factor controlling the reduction of shear modulus and damping ratio versus cyclic shear strain of wide variety of saturated soils ranging from clays to sands. From the above explanation, it can say that $G^{*}$ has a trend relating to $P I$.

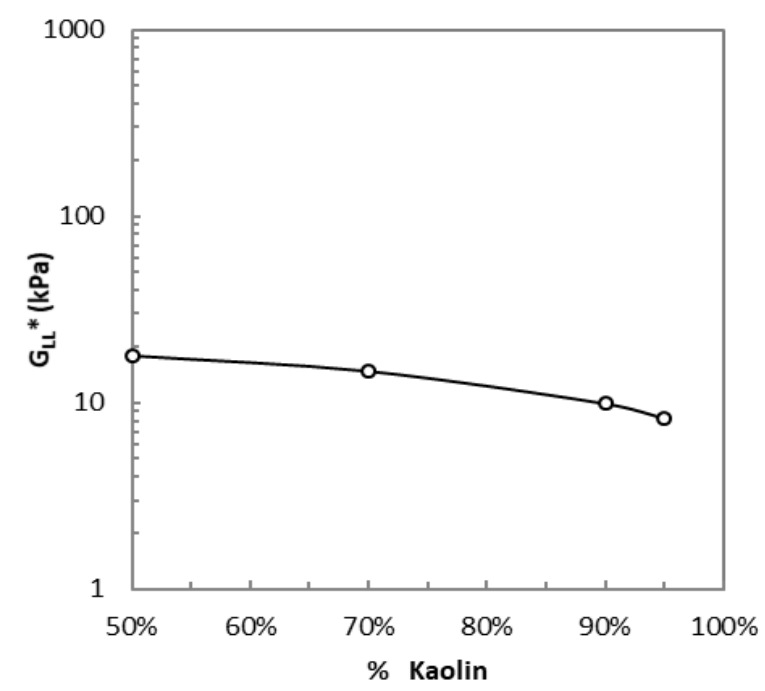

Figure 9. Complex shear modulus $\left(G_{L L}^{*}\right)$ when $L I$ is approximately $100 \%$ a frequency of $2 \mathrm{~Hz}$.

For compare complex shear modulus $\left(G_{L L}^{*}\right)$ with oedometric modulus $\left(E^{\prime}\right)$, when $L I$ is approximately $100 \%$ a frequency of $2 \mathrm{~Hz}$. It is necessary calculated from equations 4 and 5 , with the $L L$ of each mixture and the water content $(w)$ of the samples tested. The summary of the parameters estimated is presented in table 5. 
Table 5. Parameters for estimated oedometric Modulus a frequency of $2 \mathrm{~Hz}$.

\begin{tabular}{|c|c|c|c|c|c|}
\hline Mixture & $L L$ & $\begin{array}{c}w \\
(\%)\end{array}$ & $\begin{array}{l}C_{c} \\
()\end{array}$ & $\begin{array}{c}\sigma_{v}^{\prime} \\
(\mathrm{kPa})\end{array}$ & $\begin{array}{l}e \\
\text { () }\end{array}$ \\
\hline \multirow{4}{*}{1} & \multirow{4}{*}{58} & 62.99 & \multirow{4}{*}{0.41} & 2.7 & 1.69 \\
\hline & & 49.05 & & 33.8 & 1.31 \\
\hline & & 35.02 & & 438.1 & 0.94 \\
\hline & & 28.69 & & 1391.8 & 0.77 \\
\hline \multirow{4}{*}{2} & \multirow{4}{*}{76} & 74.98 & \multirow{4}{*}{0.57} & 7.53 & 2.01 \\
\hline & & 57.85 & & 50.91 & 1.55 \\
\hline & & 41.65 & & 310.73 & 1.12 \\
\hline & & 33.60 & & 762.67 & 0.90 \\
\hline \multirow{4}{*}{3} & \multirow{4}{*}{154} & 156.38 & \multirow{4}{*}{1.27} & 5.98 & 4.19 \\
\hline & & 104.15 & & 54.74 & 2.79 \\
\hline & & 59.12 & & 369.13 & 1.58 \\
\hline & & 36.69 & & 955.21 & 0.98 \\
\hline \multirow{4}{*}{4} & \multirow{4}{*}{242} & 244.88 & \multirow{4}{*}{2.06} & 6.09 & 6.56 \\
\hline & & 167.65 & & 42.83 & 4.49 \\
\hline & & 86.72 & & 330.41 & 2.32 \\
\hline & & 44.60 & & 957.13 & 1.20 \\
\hline
\end{tabular}

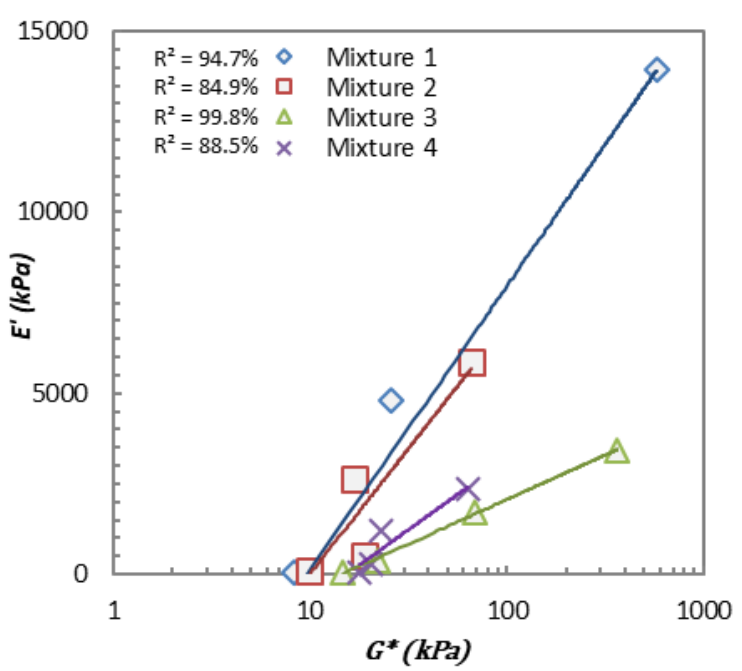

Figure 10. Correlation between Complex Modulus $\mathrm{G}^{*}$ and oedometric Modulus a frequency of $2 \mathrm{~Hz}$.

Figure 10 shows $E^{\prime}$ (calculated from equations 4 and 5) versus $G^{*}$ for different $L I$. It was found that the measured moduli $G^{*}$ correlate with moduli $E^{\prime}$. The determination coefficients between these two variables are high, and these are among $85 \%$ to $99 \%$. This correlation is specific for each mixture tested, as between mixtures there is no definite tendency. As Mayne [17] indicated in his research, the relationship between moduli depends on a constant own the soil tested (equation 6), for this paper the performance of each mixture was different. 


\section{Conclusions}

This paper presented an assessment of clayey soil mixtures with different proportions of kaolin and bentonite. The measurements were carried out in terms of rheological properties. From the analysis of the results, the following conclusions can be drawn:

- The complex modulus $G^{*}$ increases when the plasticity index increases, for samples that are above the plastic limit. This is related to the colloidal interactions within particles, as which is higher in soil mixtures with more bentonite content.

- The modulus $G^{*}$ decreases with the increase of the liquid index in clayey soils. As the samples are more fluid, their shear stiffness is lower.

- The phase angle is a measure that can explain the behaviour of the clayey soil of an easy and clear way.

- The response the clayey soils of the phase angle measured was, that it increased slightly at low and intermediate frequencies, but then decreases suddenly at high frequencies

- The Plastic Index caused an increase of its phase angle at high frequencies concerning the applied impulse. In such a way that, it changed from a response as an elastic material to a more viscoelastic one (i.e. at frequencies of $100 \mathrm{~Hz}$, the mixture 4 had a phase angle between $10^{\circ}$ and $30^{\circ}$ ). The minerals of the clays influence in the behaviour of mixes.

- In general, the samples of clayey soils presented a transition of flow for low and medium frequency. However, when the clay is in the plastic limit, it behaves as rubbery material in the same frequencies.

- The rheological properties soils are related to the flow between soil-water and mineralogical structure of the clay.

- Based on the results, the complex shear modulus correlates with the oedometric modulus for bentonite and kaolin mixtures.

With the previous conclusions, it was demonstrated that the Dynamic Shear Rheometer (used mainly in civil engineering to describe the behaviour of Visco-elastoplastic elements such as asphalt and similar) can be used to describe the behaviour of clayey soils in the plastic state (moisture between plastic limit and liquid limit). The response of clayey materials is influenced by factors as mineralogy, water content, the plasticity, and others. The plasticity limits were consistent with complex moduli under analogue conditions of strain and frequency. Based on the results of this study, the application of this methodology can be applied to other types of materials used in the construction of civil works.

\section{Acknowledgement}

This paper is a result of the research project IMP-ING-2932, funded by the research Vice-presidency of the Universidad Militar Nueva Granada. Additionally, the first authors acknowledge the financial support of the Colombian Army, in its program of scholarships for the formation of officers with Ph.D., of the Military School of Cadets "General Jose Maria Cordova".

\section{References}

[1] Atterberg, A., Uber die physikalische Bodenuntersucgung, and ubre die Plastizität der Tone, Internationale Mgen für Bodenkunde, 1 (1911).

[2] Wroth, C. P., Wood, D. M., The correlation of index properties with some basic engineering properties of soils, Canadian Geotechnical Journal, 15 (1978), 137-145.

[3] Schmitz, R. M., Schroeder, C., Charlier, R., Chemo-mechanical interactions in clay: a correlation between clay mineralogy and Atterberg limits, Applied Clay Science, 26 (2004), 351-358.

[4] Ghezzehei, T. A., Or, D., Rheological properties of wet soils and clays under steady and oscillatory stresses, Soil Science Society of America Journal, 65 (2001), 624-637.

[5] Barast, G., Razakamanantsoa, A.-R., Djeran-maigre, I., Nicholson, T., Williams, D., Swelling properties of natural and modified bentonites by rheological description, Applied Clay Science, 142 (2017), 60-68.

[6] Karmakar, S., Kushwaha, R. L., Development and laboratory evaluation of a rheometer for soil visco-plastic parameters, Journal of Terramechanics, 44 (2007), 197-204. 
[7] Casagrande, A., Research on Atterberg Limits of Soils, Public Roads, 13 (1932), 121-130.

[8] Gamboa Sosa, C. de J., Propiedades reológicas transitorias de materiales compuestos a base de polipropileno nano-reforzado con arcilla de paligorskita, Centro de Investigación Científica de Yucatán, 2017.

[9] Camacho-Tauta, J. F., Evaluation of the small-strain stiffness of soil by non-conventional dynamic testing methods, Technical University of Lisbon, PhD Thesis 2011.

[10] Pilavtepe, M., Microstructure and Rheology of Colloidal Natural Clay Mineral Dispersions, Karlsruhe Institute of Technology (KIT), 2018.

[11] Willenbacher, N., Georgieva, K., Rheology of Disperse Systems, in Product Design and Engineering: Formulation of Gels and Pastes, First Edit., U. Brockel, M. Willi, and W. Gerhard, Eds. Wiley-VCH Verlag GmbH \& Co. KGaA., 2013, 44.

[12] Goodwin, J. W., Hughes, R. W., Rheology for Chemists: An Introduction, 2nd ed. Royal Society of Chemistry: Cambridge, 2008.

[13] Cruz, N., Peng, Y., Rheology measurements for flotation slurries with high clay contents - A critical review, Minerals Engineering, 98 (2016), 137-150.

[14] Barnes, H. A., A Handbook of Elementary Rheology. The University of Wales Institute of NonNewtonian Fluid Mechanics: Aberystwyth, 2000.

[15] Mayne, P. W., Cam-clay predictions of undrained strength, Journal of the Geotechnical Engineering Division, 106 (1980), 1219-1242.

[16] Favre, J. L., Rahma, A., Classification logic and correlation between soils parameters: application to an elasto-plastic law, in Probabilities and Materials: Tests, Models and Applications, D. Breysse, Ed. Springer Netherlands: Dordrecht, 1994, 95-108.

[17] Mayne, P. W., In-situ test calibrations for evaluating soil parameters, Characterisation and Engineering Properties of Natural Soils, (2010), 1601-1652.

[18] Khaydapova, D., Milanovskiy, E., Shein, E., Rheological properties of different minerals and clay soils, Eurasian Journal of Soil Science, 4 (2015), 198-202.

[19] Arabi, A. S., Dewu, B. B. M., Oladipo, M. O. A., Funtua, I. I., Mineralogy and rheology of raw and activated Turonian to Coniacian clays from Benue Trough, northeastern Nigeria, Egyptian Journal of Petroleum, 27 (2018), 75-88.

[20] Abu-Jdayil, B., Al-Omari, S. A., Taher, H., Al-Nuaim, L., Rheological Characterization of ClayPolyester Composites, Procedia Engineering, 10 (2011), 716-721.

[21] Barnes, G. E., Workability of clay mixtures, Applied Clay Science, 153 (2018), 107-112.

[22] International ASTM, ASTM D4318 - 17e1 Standard Test Methods for Liquid Limit, Plastic Limit, and Plasticity Index of Soils, Annual Book of ASTM Standards, (2017).

[23] American Association of State Highway and Transportation Officials, Standard Method of Test for determining the rheological properties of asphalt binder using a Dynamic Shear Rheometer (DSR) T315-10, in Standard Method of Test, 2010, 32.

[24] Pritz, T., Frequency dependences of complex moduli and complex Poisson's ratio of real solid materials, Journal of Sound and Vibration, 214 (1998), 83-104.

[25] Tadros, T. F., Rheology of Dispersions: Principles and Applications. Wiley-VCH Verlag GmbH \& Co. KGaA.: Weinheim, 2010.

[26] Biot, M. A., Theory of propagation of elastic waves in a fluid-saturated porous solid., The Journal of the Acoustical Society of America, 28 (1956), 179-191.

[27] Vucetic, M., Dobry, R., Effect of soil plasticity on cyclic response, Journal of Geotechnical Engineering, 117 (1991), 89-107. 